\title{
Combating Bisexual Erasure: The Correspondence of Implicit and Explicit Sexual Identity
}

\author{
Teri A. Kirby \\ University of Exeter \\ Sally K. Merritt \\ Tulane University \\ Sarah Baillie \\ University of Washington \\ Lori Wu Malahy \\ University of Washington \\ Cheryl R. Kaiser \\ University of Washington
}

This paper, which has been accepted for publication, is not the copy of record and may not exactly replicate the final, authoritative version of the article. Please do not copy or cite this version (Nov 18, 2020) without the authors' permission.

The final, publisher-formatted version of the article can be accessed at https://journals.sagepub.com/doi/10.1177/1948550620980916

\section{Author Note}

This research was partially supported by a National Science Foundation Graduate Research Fellowship awarded to the first author; and the Economic and Social Research Council [grant number ES/S00274X/1].

The research data and materials supporting this publication are openly available from the Open Science Framework at: https://osf.io/u68tv/. The Study 2 pre-registration is available here: https://osf.io/7kfvr. 


\section{IMPLICIT SEXUAL IDENTITY}

Teri A. Kirby is a Senior Lecturer at the University of Exeter. Her research interests include diversity management, identity, stereotyping, and discrimination.

Sally K. Merritt is graduate student in the Social Psychology PhD program at Tulane University in New Orleans, Louisiana. Her research examines contributions to the underrepresentation of women and ethnic minorities in certain organizations and how and why offensive language gets communicated, interpreted, and disseminated.

Sarah Baillie completed her Bachelor's degree at the University of Washington.

Lori Wu Malahy completed her PhD at the University of Washington.

Cheryl R. Kaiser is Professor and Chair in the Department of Psychology at the University of Washington. Her research explores identity, diversity, and intergroup relations, and the intersection of these issues with civil rights law.

Corresponding author:

Teri Kirby Department of Psychology University of Exeter Exeter, Devon EX11BN United Kingom

Phone: (+44) 1392724620

E-mail: t.kirby@exeter.ac.uk 


\title{
IMPLICIT SEXUAL IDENTITY
}

\begin{abstract}
Both heterosexual and gay/lesbian individuals still question and erase bisexual identities. Skeptics contend that people adopt bisexual identities for strategic motivations, such as avoiding the stigma associated with identifying as gay or for attention-seeking purposes. Across two studies, self-identified gay $(N=168)$, straight $(N=237)$, and bisexual $(N=231)$ participants completed a sexual identity Implicit Association Test, a measure that can provide insight into automatic associations and lessen the influence of impression management strategies. All three groups displayed implicit sexual identities that were consistent with their self-ascribed identities. Gay men and lesbians implicitly identified as more gay and less bisexual than bisexual men and women, who in turn identified as less straight and more bisexual than straight men and women. These findings show that selfreported sexual identities converge with implicit identities and have implications for understanding the psychology of sexual orientation.
\end{abstract}

Keywords: Sexuality; Automatic/Implicit Processes; Self/Identity; Social Identity; Individual Differences; Prejudice/Stereotyping; Self-Concept; Self-Categorization; Social Cognition; Stigma 
IMPLICIT SEXUAL IDENTITY

\section{Combating Bisexual Erasure: The Correspondence of Implicit and Explicit Sexual Identity}

Bisexuality can be traced to antiquity. Yet both heterosexual and gay/lesbian individuals still question and erase bisexual identities (Bailey et al., 2016; Diamond et al., 2017; Maimon et al., 2019). Skeptics claim that people identifying as bisexual are experimenting or being promiscuous before settling down in heterosexual relationships or are intentionally avoiding the stigma of identifying as gay (see Rust, 2002). Self-identified bisexual individuals, however, view bisexuality as a relatively certain identity (Burke \& Lafrance, 2016; Burke \& LaFrance, 2018; but see Balsam \& Mohr, 2007), and being denied a meaningful identity has negative psychological consequences (Cheryan \& Monin, 2005). Inconsistent findings about bisexual identity (see Bailey et al., 2016), particularly on physiological reactivity to sexual stimuli, may further fuel identity denial. In contrast to perspectives designed to show divergence in physiological reactivity or behavior and identity, we test whether there is convergence between implicit (automatic associations) and explicit identity, as this approach has been central in understanding identity discrepancies (e.g., Weinstein et al., 2012) and has important implications for identity denial. Specifically, we will examine whether bisexual individuals have implicit identities reflecting their self-ascribed sexual orientation or whether they show some other pattern of implicit identity.

\section{Components of Sexual Orientation}

Multidimensional models of sexual orientation point to the importance of several components of sexual orientation, including behavior (e.g., physiological responses and sexual activity), attraction, and identity (e.g., Herek, 2000; Klein et al., 1985). Yet much of the research casting doubt on bisexuality has focused narrowly on observed behavioral measures, such as genital arousal, because they are considered more objective indicators (Savin-Williams et al., 2013). This body of evidence has been mixed, sometimes showing 


\section{IMPLICIT SEXUAL IDENTITY}

bisexual patterns of genital arousal or attention (e.g., eye gaze focused on both same and other sex sexual stimuli; Rosenthal et al., 2011), but other times showing that self-identified bisexual individuals have arousal and attentional patterns more consistent with a gay or lesbian orientation (e..g, Dawson et al., 2017; Rieger et al., 2005). Although physiological and attentional measures offer interesting insight into sexual orientation, these mixed findings may fuel skepticism about bisexuality (but see Jabbour et al., 2020), despite the limitations of assessing arousal in artificial laboratory settings.

Self-report measures of sexual orientation, such as attraction and sexual activity, have also fueled skepticism about bisexuality, with scholars noting that some bisexual individuals do not report regular sexual activity with or equal attraction to both sexes (Bailey et al., 2016). The reverse is true as well - people who are behaviorally bisexual often avoid labeling themselves as bisexual. For example, in population prevalence studies, the number of people reporting both same sex and other sex attraction or sexual activity across the lifespan is higher than the number identifying as bisexual (i.e., behavioral bisexuality; Savin-Williams \& Vrangalova, 2013). Thus, relying exclusively on self-reports of sexual activity or attraction would potentially erase the identities of bisexual-identified individuals, but it would also erase the identities of some individuals of other sexual orientations.

Identity, the cognitive component of self-concept, is an essential component of sexual orientation in its own right (Herek, 2000; Klein et al., 1985). Identity is fundamental to the psychological experience (Tajfel et al., 1971), and people strive to be viewed in line with their self-ascribed identities (e.g., Barreto et al., 2010). Consistent with self-verification theory (Swann, 2011), being denied an important identity can have negative psychological consequences, eliciting feelings of anger, threat, and defensiveness (Cheryan \& Monin, 2005). 
IMPLICIT SEXUAL IDENTITY

Counter to stereotypes about bisexual indecision, self-identified bisexual individuals themselves report that their group is similar in indecision and stability as other sexual orientation groups (Burke \& Lafrance, 2016; Burke \& LaFrance, 2018). Even within this research tradition, however, inconsistencies have emerged. For example, bisexual individuals report more identity confusion than lesbian and gay individuals when reporting about themselves instead of other bisexual individuals (Balsam \& Mohr, 2007). This increased confusion is the case for both men and women, despite suggestions that bisexuality may be

less legitimate among men (Baumeister, 2000; Chivers et al., 2004). These inconsistences and measurement complications may be why some researchers have turned to the observable behavioral measures described previously.

\section{Implicit Identity}

Implicit identity represents an alternative identity measurement that keeps identity central, but may reduce self-presentation concerns. Indeed, self-presentation concerns sometimes lead people to be less forthcoming about their attitudes or self-concept, especially for socially sensitive topics (Greenwald \& Banaji, 1995). Relative to self-report, implicit measurement can lessen the effect of strategic or external motivations or cognitions, such as fear of stigma, attention-seeking, or ideological motivations (Cvencek et al., 2010; Steffens, 2004; see Gawronski et al., 2007 for a detailed discussion of factors influencing implicit measurement).

This is consistent with dual process models arguing that mental processes can be divided into two distinct processes, those that are more automatic (implicit) and those that are more controlled (i.e., explicit; Gawronski \& Creighton, 2013). Nevertheless, implicit measurement is not a panacea, as it picks up on both controlled and automatic components of self-concept or attitudes, and ability to fake results increases with test experience (e.g., Cvencek et al., 
IMPLICIT SEXUAL IDENTITY

2010). Thus, implicit measures should not be employed as lie detection tools - they are more usefully viewed as measuring additional, but related, dimensions of self-concept and attitudes (Nosek \& Smyth, 2007), not as more accurate indicators. Accordingly, convergence between implicit and explicit identities could provide confirmation for the existence of implicit bisexual identity, but should not be used as definitive support for the legitimacy or illegitimacy of bisexuality more broadly.

Implicit measurement may nonetheless be helpful for increasing understanding of bisexuality and whether it is detectable on an automatic level. Scholars have examined a range of questions about implicit identity using measures such as the Implicit Association Test (Greenwald et al., 1998). For example, a study of transgender children, whose identities are also frequently questioned, showed that their self-reported gender identities (which are inconsistent with their sex assigned at birth) converged with their implicit gender identities (Olson et al., 2015). Only a limited number of IAT studies have examined sexual orientation (e.g., Weinstein et al., 2012), but these have also demonstrated that implicit sexual attraction usually converges with gay and heterosexual people's self-reported sexual orientation (Snowden \& Gray, 2013). To our knowledge, implicit measurement has not been used to understand bisexual identities.

\section{Present Research}

Understanding the relationship between implicit and explicit bisexual identities is important because bisexuality elicits more external doubts compared to gay and straight identities, and indeed, there may be many motivations behind adoption or rejection of a bisexual label. Stereotypes of bisexuality suggest that self-identified bisexual men may have implicit identities more consistent with being gay (because they are coming to terms with a 
IMPLICIT SEXUAL IDENTITY

gay identity) and bisexual women may have implicit identities consistent with being straight (because claims of bisexuality reflect attention-seeking or temporary experimentation; Maimon et al., 2019). However, we instead predict that bisexual individuals will show evidence of an implicit bisexual identity and neglect to show strong implicit identification as either gay/lesbian or straight. Specifically, they will implicitly identify as less gay/more straight than self-identified gay participants and more gay/less straight than straight participants, regardless of gender (Study 1). They will also directly show stronger implicit identification with a bisexual identity relative to both gay/lesbian and straight identities (Studies 2a \& 2b).

\section{Study 1}

Study 1 used an Implicit Association Test (IAT) comparing identification with gay relative to straight categories to ascertain whether a monosexual identity (gay/lesbian or straight) can sufficiently characterize bisexual individuals' implicit identification. This approach allowed us to (a) compare all three sexual orientation groups within the same IAT (which can only compare two categories within a single test), and (b) directly compare implicit and explicit identity using the sexual orientation continuum that has been used in a large portion of the sexual orientation literature (Kinsey et al., 1948). We predicted that bisexual participants' implicit identities would fall in between that of gay and straight participants. In other words, bisexual individuals would implicitly identify as less gay/more straight than self-identified gay participants and more gay/less straight than straight participants, regardless of gender. Materials and data files for both studies are available at https://osf.io/u68tv/?view_only=2cf4649fdba346b5838c1f3f30c72b54.

\section{Method}

Participants. Participants were recruited via LGBTQ listservs, social networking sites, online hobby groups, and introductory psychology courses in 2010 to participate in an 


\section{IMPLICIT SEXUAL IDENTITY}

online study ("Cognition and Social Groups") in exchange for extra psychology course credit or entry into a $\$ 50$ raffle. Of the 425 participants who consented to participate, 302 completed the study. We excluded five because $10 \%$ or more of their IAT trials were faster than 300 milliseconds (recommended by Greenwald, Nosek, \& Banaji, 2003) and another nine because they did not identify as male or female. The final sample had 79 gay ( 23 selfidentified female), 82 bisexual (59 female), and 127 straight participants ( 85 female) with a mean age of 28.62 years $(S D=13.54)$.

Sexual minority participants came disproportionately from LGBTQ listservs. These differing recruitment strategies — comparable to those used by Savin-Williams (2014) to solicit a range of sexual orientations - were necessary to ensure sufficient numbers of sexual minorities in the sample. However, the recruitment strategy may have contributed to significant differences in age, $F(2,285)=53.44, p<.001$, and racial composition, $\chi^{2}(286)=$ $31.48, p=.002$, across sexual orientation groups (see Table 1). Straight participants were younger than bisexual participants, $p<.001$, who in turn were younger than gay participants, $p<.001$. The statistical significance of the analyses reported below do not change when controlling for age and racial group ( $p$ s $<.001$ for main effects of sexual identity) - full results are reported in the supplement.

We recruited as many participants as possible in the limited time frame of one academic quarter. In order to detect a main effect of self-reported sexual orientation (gay, bisexual, and straight $)$ with a medium effect size $(f=0.25)$ and power of $1-\beta=0.80$ on implicit identity, we needed 158 participants (G*Power version 3.1.5; Faul et al., 2009). 


\section{IMPLICIT SEXUAL IDENTITY}

\section{Table 1}

Demographic Characteristics by Sexual Orientation

\begin{tabular}{lccc}
\hline Characteristic & Straight & Bisexual & Gay \\
\hline Orientation Description & & & \\
Explicit & 25 & 20 & 53 \\
Description & 9 & 10 & 4 \\
Pansexual & 0 & 2 & 0 \\
Queer & 0 & 6 & 0 \\
Questioning & 0 & 2 & 0 \\
Reject labels & 0 & 3 & 0 \\
Unspecified & 17 & 39 & 22 \\
Race (N) & & & \\
Asian & 43 & 13 & 10 \\
Black & 1 & 1 & 4 \\
Latino/a/x & 5 & 1 & 2 \\
Native American & 2 & 1 & 0 \\
White & 58 & 57 & 58 \\
Other & 3 & 2 & 2 \\
Multiracial & 14 & 7 & 2 \\
Gender & & & \\
Female & 85 & 59 & 23 \\
Male & 42 & 23 & 56 \\
Age in Years & & & \\
Mean & 21.54 & 29.90 & 38.66 \\
SD & 5.81 & 12.72 & 16.34 \\
\hline
\end{tabular}

Note. Explicit refers to participants who explicitly used one of the sexual orientation labels above (straight/heterosexual, bisexual, or homosexual/gay/lesbian). Description refers to participants who described their orientation in a way that mapped onto that grouping (e.g., "attracted to women"). Some participants did not specify their sexual orientation, so we classified them on the basis of responses to the sexual identification scale. Specifically, we classified those responding at the extremes of the scale as straight and gay ("exclusively straight" and "exclusively gay," respectively) and everyone in between as bisexual, in line with other research (e.g., Rieger, Chivers, \& Bailey, 2005). 
IMPLICIT SEXUAL IDENTITY

Procedure. After learning that the study examined people's preferences, attitudes, and performance on cognitive tasks, participants completed explicit measures, followed by the implicit measure.

\section{Explicit sexual orientation}

Sexual orientation. Participants described their sexual orientation in an open-ended question ("What is your sexual orientation?"). To obtain a categorical measure for analysis, we classified participants into straight, gay, or bisexual categories, unless they did not fall into any of these categories (e.g., asexual). In this study, like Galupo, Ramirez, and PuliceFarrow (2017), we used bisexual as an umbrella term for various plurisexual identities, such as bisexual and pansexual (see Table 1 for a breakdown) - we also classified participants as bisexual if they expressed any interest in both the same and other sex (e.g., "I believe that I am a 2 on the Kinsey scale. This means I'm straight but have interest in homosexual relations."). This strategy, which created more variability and potentially worked against our hypotheses, allowed us to maximize our sample size. However, results were parallel when limiting analyses specifically to those who used the term bisexual - further details are in the online supplement.

Sexual attraction, behavior, fantasies, and identity. We used four Kinsey Scales (Kinsey et al., 1948; Miller et al., 2008) as an alternative way of understanding sexual orientation and how it relates to implicit sexual identity. Participants rated their sexual attraction ("Which sex/es are you attracted to?"), sexual fantasies ("Whether they occur in fantasies, daydreams or in dreams, which sex/es are in your fantasies?"), and sexual behavior (e.g., "with whom do you engage in sexual activity [not just intercourse]?”) on a 7-point scale where $-3=$ Other sex, $-2=$ Other sex mostly, $-1=$ Other sex somewhat more, $0=$ Both sexes equally, 1 = Same sex somewhat more, 2 = Same sex mostly, $3=$ Same sex only. They also responded to "How do you label/identify yourself?" on a 7-point scale from -3 = Exclusively 
IMPLICIT SEXUAL IDENTITY

straight to $3=$ Exclusively gay. These items were highly correlated, $r \mathrm{~s}>.85$ (see Table 2 for correlations), but they represent conceptually distinct aspects of sexual orientation (see Bailey et al., 2016).

\section{Implicit sexual identity}

We used the Implicit Association Test (IAT; Greenwald, McGhee, \& Schwartz, 1998) to measure whether participants associated themselves more strongly with being gay as compared to straight. Across two block types in a counterbalanced order, participants classified images of couples holding hands or kissing into the target categories "straight" or "gay" and word stimuli into the target categories "self" (e.g., me, mine) or "other" (e.g., other, them). In one block type, they pressed the right key when gay or self target words appeared in the center of the screen (and the left key for straight and other); in the other block type, they pressed the right key for straight or self target words. In line with BrinsmeadStockham, Johnston, Miles, and Macrae (2008), we matched the "gay" stimuli to participants' self-reported gender. Specifically, male participants viewed images of two men holding hands or kissing, while female participants viewed equivalent images of two women.

Participants classifying gay and self words together more quickly than straight and self words were considered to have a stronger gay than straight identity. The IAT was scored using the D measure (Greenwald, Nosek, \& Banaji, 2003) so that positive values corresponded to stronger gay identity.

\section{Results}

Preliminary analyses. We first examined the distributions of implicit and explicit sexual identity separately for men and women (see Figure 1) to understand whether the implicit and explicit distributions were comparable. Women's explicit sexual identity had a positively skewed distribution (skewness $=0.87, S E=.19, p<.001$ ), such that most women identified as exclusively straight. Men's explicit sexual identity was not significantly skewed 


\section{IMPLICIT SEXUAL IDENTITY}

(skewness $=-0.26, S E=.22, p=.12$ ), but visual inspection showed a bimodal distribution, with most participants identifying as exclusively straight or gay. Indeed, Hartigan's dip test (Hartigan \& Hartigan, 1985) rejected unimodality for men $(\operatorname{dip}=0.16, p<.001)$ and women $(\operatorname{dip}=0.08, p<.001)$.

Implicit sexual identity did not match these patterns. The distributions were unimodal for women $(\operatorname{dip}=0.02, p=.85)$ and men $(\operatorname{dip}=0.04, p=.24)$ and not significantly skewed for women (skewness $=0.28, S E=.19, p=.14)$ or men (skewness $=-0.28, S E=.22, p=.31)$. These normal distributions give an initial suggestion that implicit sexual orientation shows less of a binary distribution than do self-reports of sexual orientation. 
Women
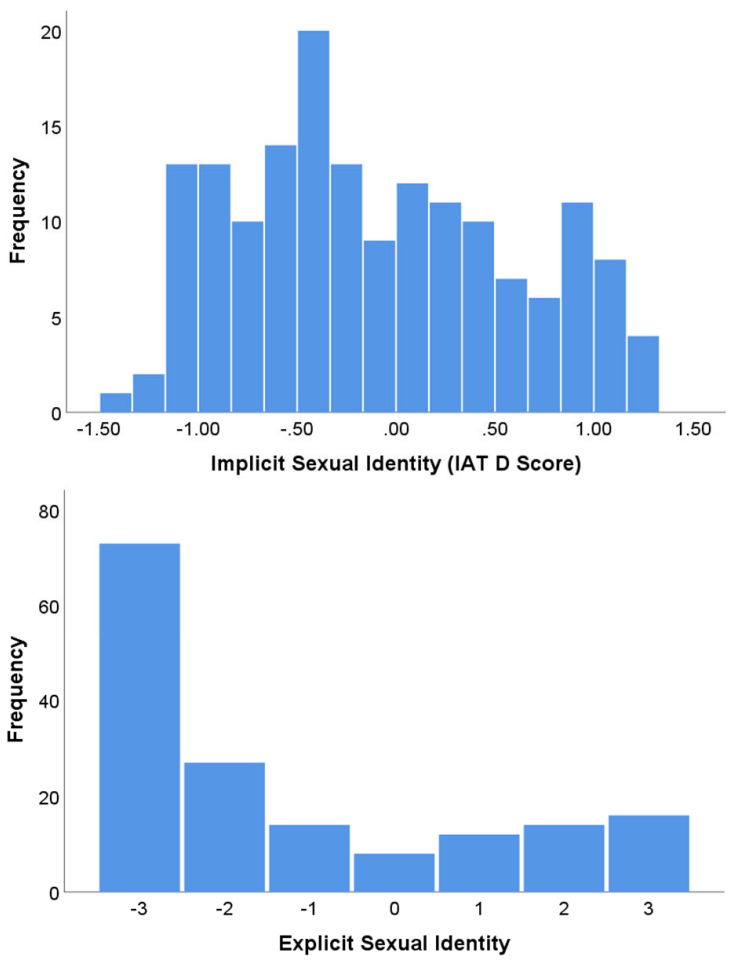

Men
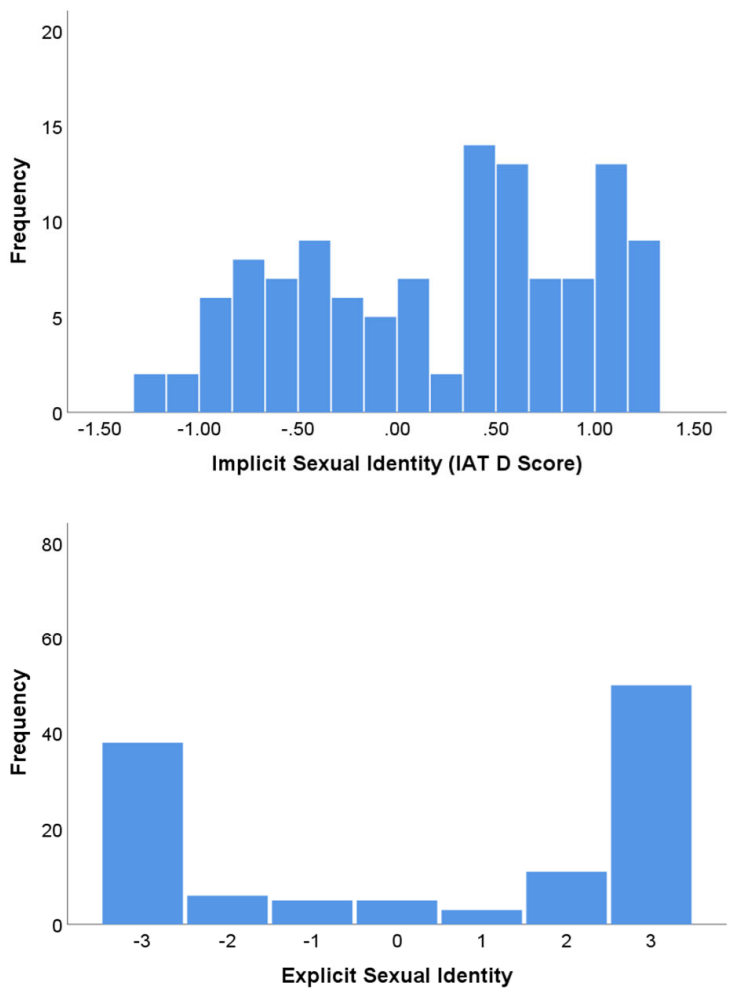

Figure 1. Histogram of implicit and explicit sexual identity for all participants. 


\section{IMPLICIT SEXUAL IDENTITY}

We next examined correlations between implicit identity and explicit measures of sexual orientation in Table 2. As participants implicitly identified as more gay (as compared to straight), they reported a stronger gay orientation on all explicit sexual orientation measures $r \mathrm{~s}>.68, p \mathrm{~s}<.001$. These strong relationships are comparable to other research measuring implicit and explicit identity (Hofmann et al., 2005), which suggests strong implicit-explicit consistency despite sexual orientation being socially sensitive. 


\section{IMPLICIT SEXUAL IDENTITY}

Table 2

Bivariate Correlations, Means, and Standard Deviations for All Measures

\begin{tabular}{lccccc}
\hline \multicolumn{1}{c}{ Measure } & 2 & 3 & 4 & 5 & Mean $(S D)$ \\
\hline 1. Implicit Sexual Id & $0.73^{* *}$ & $0.73^{* *}$ & $0.68^{* *}$ & $0.79^{* *}$ & $0.04(0.72)$ \\
2. Sexual Attraction & - & $0.94^{* *}$ & $0.93^{* *}$ & $0.91^{* *}$ & $-0.31(2.53)$ \\
3. Sexual Behavior & - & $0.85^{* *}$ & $0.87^{* *}$ & $-0.46(2.70)$ \\
4. Sexual Fantasies & & - & $0.86^{* *}$ & $-0.25(2.45)$ \\
5. Explicit Sexual Id & & & - & $-0.55(2.52)$ \\
\hline
\end{tabular}

Note. Ns range from 254 to 288 .

$* p \leq .01 .{ }^{* *} p \leq .001$. 


\section{IMPLICIT SEXUAL IDENTITY}

\section{Differences in implicit sexual identity by orientation}

Analytic strategy. To determine whether self-identified gay, bisexual, and straight participants differed on implicit sexual identity, we conducted two sets of 3 (sexual orientation: straight, bisexual, gay) x 2 (gender) ANOVAs. In the first analysis, we used sexual orientation as classified by the open-ended self-report measure. For the second analysis, we determined sexual orientation through a hierarchical cluster analysis that separated men and women into three sexual orientation categories (straight $n=131$; bisexual $n=40$; gay/lesbian $n=111$ ) based on the combination of responses they gave on continuous measures of self-reported sexual attraction, behavior, fantasies, and identity. The analysis used squared Euclidean distances with Ward linkage.

Sexual orientation classified by open-ended self-report. As expected, we found a main effect of sexual orientation on implicit sexual identity, $F(2,282)=152.92, p<.001$, with no moderation by gender, $F(2,282)=0.89, p=.41$. Self-identified gay participants implicitly identified as more gay than bisexual participants, $d=1.17,95 \% \mathrm{CI}[0.41,0.77], p$ $<.001$, who in turn identified as more gay (and less straight) than straight participants, $d=$ $1.30,95 \%$ CI $[1.11,1.44], p<.001$, in a Tukey-Kramer post hoc comparison test (see Figure

2). These results suggest consistency between implicit sexual identity and self-reported orientation. It is also inconsistent with lay stereotypes of bisexual-identified men avoiding a gay identity or straight women identifying as bisexual for attention-seeking purposes. 
IMPLICIT SEXUAL IDENTITY

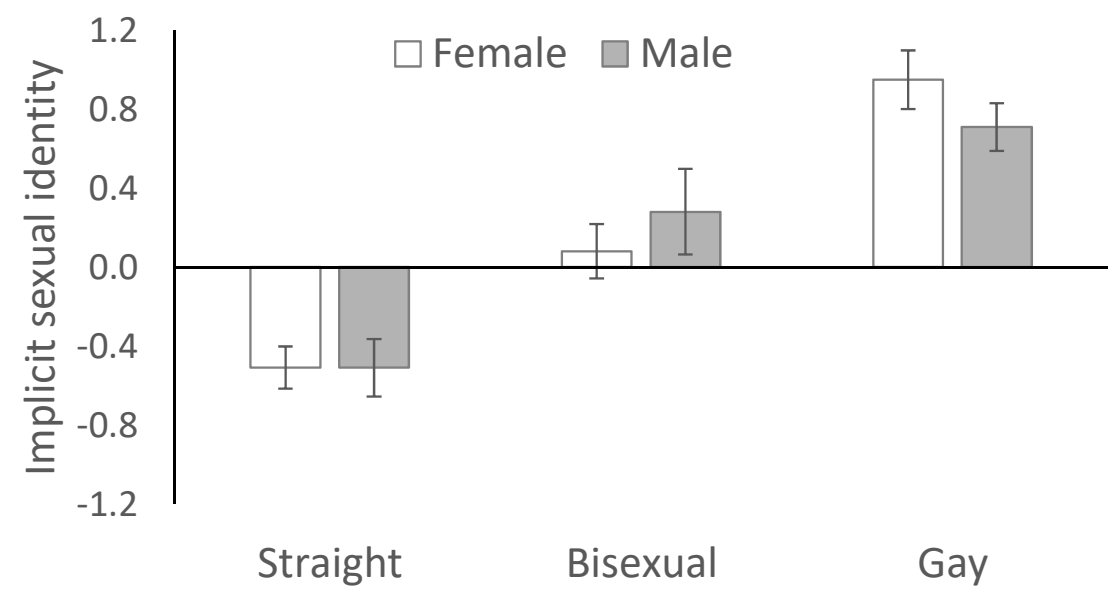

Figure 2. Implicit sexual identity by open-ended sexual orientation and gender. Values greater than 0 indicate a stronger gay/self association. 
IMPLICIT SEXUAL IDENTITY

\section{Sexual orientation based on cluster analysis of attraction, behavior, fantasies, and}

identity. We also examined implicit sexual identity using an alternative measure of sexual orientation. We first conducted a cluster analysis that separated men and women into three sexual orientation categories (straight $n=131$; bisexual $n=40$; gay/lesbian $n=111$ ) based on their self-reported sexual attraction, behavior, fantasies and identity on a continuum (analysis details are in the online supplement).

We conducted the same 3 (sexual orientation: straight, bisexual, gay) x 2 (gender) ANOVA and found a main effect of sexual orientation on implicit sexual identity, $F(2,276)$ $=147.00, p<.001$ (see Figure 3). Gay participants implicitly identified as more gay than bisexual participants, $p<.001,95 \%$ CI $[0.41,0.78], d=1.10$, who in turn identified as more gay than straight participants, $p<.001,95 \%$ CI $[0.34,0.71], d=1.24$, in Tukey-Kramer post hoc comparison tests (see Figure 3).

In contrast to the previous analysis, gender moderated the effect of sexual orientation, $F(2,276)=3.24, p=.04$. Examining simple effects by gender showed the same pattern of findings for men and women. For both men, $F(2,276)=76.08, p<.001$, and women, $F(2$, 276) $=80.70, p<.001$, self-identified gay participants implicitly identified as more gay than bisexual men, $d=1.90,95 \%$ CI $[0.54,1.12], p<.001$, and women, $d=0.63,95 \%$ CI $[0.12$, $0.58], p=.003$, who in turn identified as more gay than straight men, $d=0.64,95 \% \mathrm{CI}[0.03$, 0.64], $p=.03$, and women, $d=1.59,95 \%$ CI $[0.50,0.92], p<.001$, in a Tukey-Kramer post hoc comparison test.

When decomposing by sexual orientation to examine gender differences, selfidentified gay men implicitly identified as more gay/lesbian than did lesbians, $F(1,276)=$ $4.30, p=.04, d=0.39,95 \%$ CI $[0.01,0.38]$. There was no gender difference for straight, $F(1$, $276)=1.03, p=.31, d=.20,95 \%$ CI $[-0.09,0.27]$ or bisexual participants, $F(1,276)=3.04$, 


\section{IMPLICIT SEXUAL IDENTITY}

$p=.08, d=0.57,95 \% \mathrm{CI}[-0.04,0.61]$. These findings also suggest consistency between implicit sexual identity and self-reported sexual orientation. 


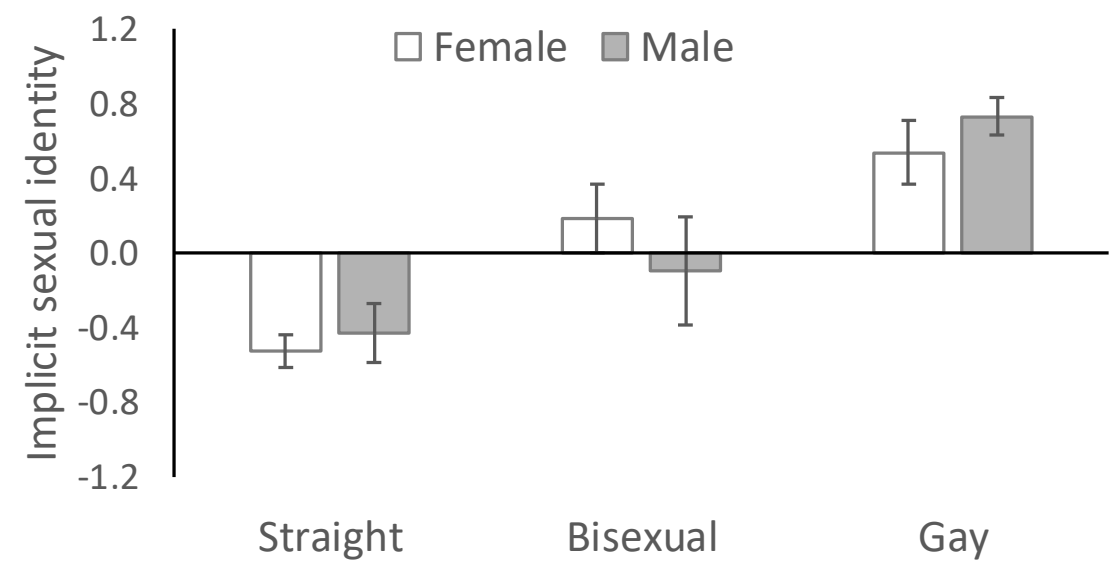

Figure 3. Implicit sexual identity by sexual orientation clusters and gender. Values greater than 0 indicate a stronger gay/self association. 
IMPLICIT SEXUAL IDENTITY

\section{Discussion}

Comparing the implicit identities of bisexual, gay, and straight individuals within the same IAT required using an identity spectrum from gay to straight. Albeit useful for comparison, this approach prevented us from directly assessing implicit bisexuality. It also relegated bisexual individuals to an intermediate identity, rather than acknowledging their bisexuality as a unique identity in its own right. In Study 2, we used IATs that directly assessed implicit bisexual identities, as opposed to treating identity as a continuum (with bisexuality as an intermediate category).

\section{Study 2}

In Study 2a, bisexual and straight participants completed an IAT measuring identification with bisexual as compared straight categories. In Study 2b, bisexual and gay/lesbian participants completed an IAT measuring identification with bisexual as compared gay/lesbian categories.

\section{Method}

Participants. Participants were recruited in 2019 via Prolific Academic, an online participant recruitment platform, to participate in a study ("Word Classification Task") in exchange for $£ 1.00$ (GBP). Because the IAT involves rapid classification of words, we restricted the study to native English speakers. We also restricted to bisexual, heterosexual, and homosexual sexual orientation and to male or female sex and gender identity.

A G*Power analysis for an ANOVA with main effects and interactions suggested that 128 participants would be needed for each study to detect a medium effect $(f=0.25)$ at $\alpha=$ .05 and power $=0.8$. We instead pre-registered (https://osf.io/qp3tu/?view_only=fdf78230a2114632835c2e0c3672d6d2) and recruited a higher sample size of 50 participants per group (i.e., 50 each of lesbians, gay men, bisexual 
IMPLICIT SEXUAL IDENTITY

women and men, and straight women and men), for a total of 200 participants in Study 2a and 200 in Study 2b. We excluded one participant in Study $2 \mathrm{a}$ and six in $2 \mathrm{~b}$ because $10 \%$ or more of their IAT trials were faster than 300 milliseconds, as well as fifteen in Study 2a and thirty in Study $2 \mathrm{~b}$ who did not identify as straight, gay/lesbian, or bisexual. We excluded four participants in Study 2a because English was not their first language, leaving a final sample of 180 participants in Study $2 \mathrm{a}$ and 164 in Study $2 \mathrm{~b}$.

In Study 2a, the sample comprised 74 bisexual (39 female) and 110 straight (54 female) participants $\left(M_{\mathrm{age}}=33.54, S D=12.60\right)$, of whom $90 \%$ were White (with the remaining 2\% Black, 3\% Multiracial, 2\% Latinx, and 3\% Asian). Study 2b comprised 75 bisexual (40 female) and 89 gay participants (43 female; $M_{\text {age }}=31.52, S D=11.14$ ), of whom 90\% were White (with the remaining 4\% Black, $3 \%$ Multiracial, 3\% Latinx, and 1\% Asian).

Procedure. Participants completed an IAT (IatGen for Qualtrics; Carpenter et al., 2018) and explicit measures in a counterbalanced order. The IAT measured whether participants associated themselves more strongly with bisexual as compared to straight identities in Study 2a and bisexual as compared to gay in Study 2b. In both studies, participants classified the same word stimuli from Study 1 into the attribute categories "self" or "other." They also classified words into the target categories of "bisexual" (e.g., bisexuality, bi), "straight” (heterosexual, heterosexuality), “gay” (e.g., homosexual, homosexuality), or "lesbian" (e.g., homosexual, homosexuality), depending on the study. Participants classifying bisexual and self words together more quickly than straight or gay/lesbian and self words were considered to have a stronger bisexual than straight or gay/lesbian identity. All IATs were scored using the D measure so that positive values corresponded to stronger bisexual identity.

Afterwards, participants reported their sexual orientation ("Please choose the option that best describes your sexual orientation)" with the options gay/lesbian, straight, bisexual, 
IMPLICIT SEXUAL IDENTITY

pansexual, asexual, queer. As described above, we removed any participants who did not select straight, bisexual, or gay/lesbian. Participants also responded to the same explicit identity, attraction, fantasy, and behavior measures from Study 1. These measures were exploratory (see pre-registration) and are only described in the online supplement.

\section{Study 2a Results}

Differences in implicit sexual identity by self-reported sexual orientation. To determine whether self-identified bisexual and straight participants differed on implicit sexual identity, we conducted a 2 (explicit sexual identity: bisexual vs. straight) x 2 (gender: male vs. female) ANOVA. As expected, we found a main effect of explicit sexual identity on implicit sexual identity, $F(1,176)=20.03, p<.001$, with no moderation by gender, $F(1,176)$ $=1.66, p=.20$. Self-identified bisexual participants implicitly identified as more bisexual than straight participants, $d=0.68,95 \%$ CI [-0.80,-0.55], $p<.001$.

In addition, we conducted a one-sample t-test to determine whether each group significantly identified with their self-ascribed identity on an implicit level (as demonstrated by a significant difference from the IAT neutral point of 0$)$. Indeed, both bisexual, $t(73)=$ $3.76, p<.001, d=0.43$, and straight individuals, $t(105)=-12.40, p<.001, d=1.20$, showed implicit identities consistent with their respective self-ascribed identities.

\section{Study 2b Results}

\section{Differences in implicit sexual identity by self-reported sexual orientation. To} determine whether self-identified bisexual and gay participants differed on implicit sexual identity, we conducted a 2 (explicit sexual identity: bisexual vs. gay) x 2 (gender: male vs. female) ANOVA. As expected, we found a main effect of explicit sexual identity on implicit sexual identity, $F(1,160)=135.03, p<.001$, with no moderation by gender, $F(1,160)=$ $0.004, p=.95$. Self-identified bisexual participants implicitly identified as more bisexual than gay and lesbian participants, $d=0.73,95 \%$ CI [-0.86,-0.61], $p<.001$. 
IMPLICIT SEXUAL IDENTITY

In one-sample t-tests, bisexual individuals also significantly associated themselves with bisexuality, $t(74)=3.92, p<.001, d=0.45$, and gay/lesbian individuals associated themselves with gay/lesbian, $t(88)=-13.23, p<.001, d=1.41$. These results suggest consistency between implicit sexual identity and self-reported identity.

\section{General Discussion}

Bisexual erasure persists in western society. Nevertheless, self-reported sexual orientation converges with implicit identity among bisexual, straight, and gay men and women. Specifically, self-identified gay men and women implicitly identify as more gay and less bisexual than bisexual men and women, who in turn identify as more bisexual and less straight than straight men and women. Bisexual individuals also identify as more bisexual than gay or straight. Implicit sexual identity maps onto explicit sexual orientation when measured not only through self-reported orientation, but also when determined through a combination of identity, attraction, sexual behavior, and fantasies.

Understanding bisexuality is important because bisexual people are especially susceptible to having their self-professed identity denied, by both sexual majority and minority perceivers alike. This identity denial is linked with negative outcomes (Cheryan \& Monin, 2005), such as reduced motivation and self-esteem (Townsend et al., 2009), which may be one reason that bisexual individuals face disproportionally poor health outcomes even relative to gay and lesbian individuals (Dodge et al., 2016).

Because much of the psychological literature has focused on those at the endpoints of identity spectrums (see Burke \& Lafrance, 2016), research with bisexual, biracial, non-binary gender identities, and other intermediate identities have been neglected. Although "intermediate" group members sometimes show identity patterns in between that of group members at the endpoints, this is not always the case. For example, bisexual individuals perceive themselves as more similar to straight people in terms of masculinity versus 
IMPLICIT SEXUAL IDENTITY

femininity, not as in between gay and straight people (Burke \& Lafrance, 2016). Yet, in the present research, they showed a pattern that was distinct from both gay and straight individuals on implicit measures, speaking to the psychological importance of acknowledging their distinct identities. It is essential to gain a more complex understanding of the selfconcepts of sexual minorities using a variety of methodological approaches.

Despite the current findings, implicit and explicit sexual identity may not always align for bisexual individuals because people cope with stigmatized identities in complex ways. For example, people may identify as bisexual, but not consider it central to their self-concept, which could inhibit the development of bisexuality on an implicit level. Similarly, people may view sexual orientation as a behavioral pattern or a personal identity rather than a social identity. Indeed, some sexual minorities attempt to blend in with heterosexual individuals and do not see their sexual orientation as relevant to other aspects of their lives (Cox \& Gallois, 1996). Bisexual individuals in particular come to their identity at a later age (Rust, 1993) and do not always feel a sense of belonging with the LGBTQ community (Hayfield et al., 2014). Finally, bisexual individuals might feel that the bisexual label does not fully match their selfconcept - indeed, many sexual minorities find sexuality labels suboptimal or reject them entirely (Galupo et al., 2017).

Thus, it is important to avoid strong conclusions about an identity based solely on convergence between implicit and explicit identity measures (or lack thereof) in a single set of studies. A wider range of measurement approaches and sampling strategies are needed to fully understand the self-concepts of sexual minority groups.

\section{Limitations and Future Directions}

Our categorizations of sexual orientation did not fully reflect the diversity of identities, especially because many people view sexuality as a continuum (Kinsey et al., 
IMPLICIT SEXUAL IDENTITY

1948) or as fluid (see Galupo et al., 2017 for a discussion of limitations of monosexual continuums). In Study 1 in particular, some participants explicitly rejected orientation labels or viewed their orientation as fluid (see Diamond et al., 2017). When restricting more narrowly to bisexual-identified participants in Study 2, our conclusions about implicit identity were the same. Nonetheless, the distinctions across these groups (which may not generalize outside of western contexts) should be explored in future research.

Finally, our cross-sectional design precludes drawing any conclusions as to whether bisexuality is a transitory state. Although longitudinal research on implicit sexual identity would help address this limitation, longitudinal research on explicit sexual identity has already demonstrated little support for bisexuality as a transitional stage for bisexual women (Diamond, 2008).

\section{Conclusion}

Although negative attitudes toward the gay and lesbian community have declined in recent years, attitudes toward bisexual individuals have not followed suit, perhaps due to questions around the legitimacy of their identity (Dodge et al., 2016). Rather than confirming stereotypes that bisexual individuals are merely experimenting, avoiding the stigma of identifying as gay, or looking for attention, this research showed that their self-concepts were distinct from gay and straight individuals on implicit measures and reflected a distinct bisexual identity. Demonstrating that both bisexual men and women show a pattern of implicit identity separate from that of straight and gay individuals is an important step toward understanding bisexual self-concept and reducing the unique stigma associated with bisexuality. 
IMPLICIT SEXUAL IDENTITY

\section{References}

Bailey, J. M., Vasey, P. L., Diamond, L. M., Breedlove, S. M., Vilain, E., \& Epprecht, M. (2016). Sexual orientation, controversy, and science. Psychological Science in the Public Interest, 17(2), 45-101. https://doi.org/10.1177/1529100616637616

Balsam, K. F., \& Mohr, J. J. (2007). Adaptation to sexual orientation stigma: A comparison of bisexual and lesbian/gay adults. Journal of Counseling Psychology, 54(3), 306-319. https://doi.org/10.1037/0022-0167.54.3.306

Barreto, M., Ellemers, N., Scholten, W., \& Smith, H. (2010). To be or not to be: the impact of implicit versus explicit inappropriate social categorizations on the self. The British Journal of Social Psychology, 49, 43-67. https://doi.org/10.1348/014466608X400830

Baumeister, R. (2000). Gender differences in erotic plasticity: The female sex drive as socially flexible and responsive. Psychological Bulletin, 126(3), 347-374. https://doi.org/10.1037/0033-2909.126.3.347

Brinsmead-Stockham, K., Johnston, L., Miles, L., \& Macrae, C. (2008). Female sexual orientation and menstrual influences on person perception. Journal of Experimental Social Psychology, 44(3), 729-734. https://doi.org/10.1016/j.jesp.2007.05.003

Burke, S., \& Lafrance, M. (2016). Stereotypes of bisexual people: What do bisexual people themselves think? Psychology of Sexual Orientation and Gender Diversity, 3(2), 247254. https://doi.org/10.1037/sgd0000168

Burke, S., \& LaFrance, M. (2018). Perceptions of instability and choice across sexual orientation groups. Group Processes and Intergroup Relations, 21(2), 257-279. https://doi.org/10.1177/1368430216663019

Cheryan, S., \& Monin, B. (2005). "Where are you really from?”: Asian Americans and 


\section{IMPLICIT SEXUAL IDENTITY}

identity denial. Journal of Personality and Social Psychology, 89(5), 717-730.

https://doi.org/10.1037/0022-3514.89.5.717

Chivers, M., Rieger, G., Latty, E., \& Bailey, J. M. (2004). A sex difference in the specificity of sexual arousal. Psychological Science, 15(11), 736-744.

https://doi.org/10.1111/j.0956-7976.2004.00750.x

Cox, S., \& Gallois, C. (1996). Gay and lesbian identity development : A social identity perspective. Journal of Homosexuality, 30(4), 1-30. https://doi.org/10.1300/J082v30n04

Cvencek, D., Greenwald, A. G., Brown, A. S., Gray, N. S., \& Snowden, R. J. (2010). Faking of the Implicit Association Test is statistically detectable and partly correctable. Basic and Applied Social Psychology, 32(4), 302-314.

https://doi.org/10.1080/01973533.2010.519236

Dawson, S. J., Fretz, K. M., \& Chivers, M. (2017). Visual attention patterns of women with androphilic and gynephilic sexual attractions. Archives of Sexual Behavior, 46(1), 141153. https://doi.org/10.1007/s10508-016-0825-0

Diamond, L. M. (2008). Female Bisexuality From Adolescence to Adulthood: Results From a 10-Year Longitudinal Study. Developmental Psychology, 44(1), 5-14. https://doi.org/10.1037/0012-1649.44.1.5

Diamond, L. M., Dickenson, J. A., \& Blair, K. L. (2017). Stability of sexual attractions across different timescales: The roles of bisexuality and gender. Archives of Sexual Behavior, 46(1), 193-204. https://doi.org/10.1007/s10508-016-0860-x

Dodge, B., Herbenick, D., Friedman, M. R., Schick, V., Fu, T. C., Bostwick, W., Bartelt, E., Muñoz-Laboy, M., Pletta, D., Reece, M., \& Sandfort, T. G. M. (2016). Attitudes toward bisexual men and women among a nationally representative probability sample of adults 


\section{IMPLICIT SEXUAL IDENTITY}

in the United States. PLOS ONE, 11(10), 1-18.

https://doi.org/10.1371/journal.pone.0164430

Faul, F., Erdfelder, E., Buchner, A., \& Lang, A. (2009). Statistical power analyses using G*Power 3.1 : Tests for correlation and regression analyses. Behavior Research Methods, 41(4), 1149-1160. https://doi.org/10.3758/BRM.41.4.1149

Galupo, M. P., Ramirez, J. L., \& Pulice-Farrow, L. (2017). “Regardless of their gender”: Descriptions of sexual identity among bisexual, pansexual, and queer identified individuals. Journal of Bisexuality, 17(1), 108-124. https://doi.org/10.1080/15299716.2016.1228491

Gawronski, B., \& Creighton, L. A. (2013). Dual Process Theories. In D. E. Carlston (Ed.), The Oxford Handbook of Social Cognition (pp. 282-312). Oxford University Press.

Gawronski, B., LeBel, E. P., \& Peters, K. R. (2007). What do implicit measures tell us? Scrutinizing the validity of three common assumptions. Perspectives on Psychological Science, 2(2), 181-193. https://doi.org/10.1111/j.1745-6916.2007.00036.x

Greenwald, A., Nosek, B., \& Banaji, M. (2003). Understanding and using the Implicit Association Test: I. An improved scoring algorithm. Journal of Personality and Social Psychology, 85(2), 197-216. https://doi.org/10.1037/0022-3514.85.2.197

Greenwald, A.G., Mcghee, D. E., \& Schwartz, J. L. . (1998). Measuring individual differences in implicit cognition: The Implicit Association Test. Journal of Personality and Soclal Psychology, 74(6), 1464-1480. https://doi.org/OO22-3514/98

Greenwald, Anthony G, \& Banaji, M. R. (1995). Implicit social cognition: Attitudes, selfesteem, and stereotypes. Psychological Review, 102(1), 4-27. https://doi.org/0033$295 \mathrm{X} / 95$ 
IMPLICIT SEXUAL IDENTITY

Hartigan, J., \& Hartigan, P. (1985). The dip test of unimodality. Annals of Statistics, 13(1), $70-84$.

Hayfield, N., Clarke, V., \& Halliwell, E. (2014). Bisexual women's understandings of social marginalisation: "The heterosexuals don't understand US but nor do the lesbians." Feminism and Psychology, 24(3), 352-372. https://doi.org/10.1177/0959353514539651

Herek, G. M. (2000). Homosexuality. In A. E. Kazdin (Ed.), Encyclopedia of Psychology (pp. 149-153). American Psychological Association.

Hofmann, W., Gawronski, B., Gschwendner, T., Huy, L., \& Schmitt, M. (2005). A MetaAnalysis on the Correlation Between the Implicit Association Test and Explicit SelfReport Measures. Personality and Social Psychology Bulletin, 31(10), 1369-1385. https://doi.org/10.1177/0146167205275613

Jabbour, J., Holmes, L., Sylva, D., Hsu, K. J., Semon, T. L., Rosenthal, A. M., Safron, A., Slettevold, E., Watts-Overall, T. M., Savin-Williams, R. C., Sylla, J., Rieger, G., \& Bailey, J. M. (2020). Robust evidence for bisexual orientation among men. Proceedings of the National Academy of Sciences of the United States of America, 117(31), 1836918377. https://doi.org/10.1073/pnas.2003631117

Kinsey, A. C., Pomeroy, W. B., Martin, C. E., \& Sloan, S. (1948). Sexual behavior in the human male. W.B. Saunders.

Klein, F., Sepekoff, B., \& Wolf, T. J. (1985). Sexual Orientation: A Multi-Variable Dynamic Process. Journal of Homosexuality, 11(1), 35-49. https://doi.org/10.1300/J082v11n01

Maimon, M. R., Sanchez, D. T., Albuja, A. F., \& Howansky, K. (2019). Bisexual identity denial and health: Exploring the role of societal meta-perceptions and belonging threats among bisexual adults. Self and Identity, 00(00), 1-13. 


\section{IMPLICIT SEXUAL IDENTITY}

https://doi.org/10.1080/15298868.2019.1624275

Miller, S. S., Hoffmann, H. L., \& Mustanski, B. S. (2008). Fluctuating asymmetry and sexual orientation in men and women. Archives of Sexual Behavior, 37(1), 150-157. https://doi.org/10.1007/s10508-007-9256-2

Nosek, B. A., \& Smyth, F. L. (2007). A Multitrait-Multimethod Validation of the Implicit Association Test: Implicit and Explicit Attitudes Are Related but Distinct Constructs. Experimental Psychology, 54(1), 14-29. https://doi.org/10.1027/1618-3169.54.1.14

Olson, K. R., Key, A. C., \& Eaton, N. R. (2015). Gender cognition in transgender children. Psychological Science, 26(4), 467-474. https://doi.org/10.1177/0956797614568156

Rieger, G., Chivers, M., \& Bailey, J. M. (2005). Sexual arousal patterns of bisexual men. Psychological Science, 16(8), 579-584. https://doi.org/10.1111/j.14679280.2005.01578.x

Rosenthal, A. M., Sylva, D., Safron, A., \& Bailey, J. M. (2011). Sexual arousal patterns of bisexual men revisted. Biological Psychology, 88, 112-115. https://doi.org/10.1016/j.biopsycho.2011.06.015

Rust, P. C. (1993). "Coming out" in the age of social constructionism: Sexual identity formation among lesbian and bisexual women. Gender \& Society, 7(1), 50-77.

Rust, P. C. (2002). Bisexuality: The state of the union. Annual Review of Sex Research, 13(November), 180-240. https://doi.org/10.1080/10532528.2002.10559805

Savin-Williams, R. C. (2014). An exploratory study of the categorical versus spectrum nature of sexual orientation. Journal of Sex Research, 51(4), 446-453. https://doi.org/10.1080/00224499.2013.871691 


\section{IMPLICIT SEXUAL IDENTITY}

Savin-Williams, R. C., Rieger, G., \& Rosenthal, a. M. (2013). Physiological evidence for a mostly heterosexual orientation among men. Archives of Sexual Behavior, 42, 697-699. https://doi.org/10.1007/s10508-013-0093-1

Savin-Williams, R. C., \& Vrangalova, Z. (2013). Mostly heterosexual as a distinct sexual orientation group: A systematic review of the empirical evidence. Developmental Review, 33(1), 58-88. https://doi.org/10.1016/j.dr.2013.01.001

Snowden, R. J., \& Gray, N. S. (2013). Implicit sexual associations in heterosexual and homosexual women and men. Archives of Sexual Behavior, 42, 475-485. https://doi.org/10.1007/s10508-012-9920-z

Steffens, M. C. (2004). Is the implicit association test immune to faking? Experimental Psychology, 51(3), 165-179. https://doi.org/10.1027/1618-3169.51.3.165

Swann, W. B. (2011). Self-verification theory. In Handbook of Theories of Social Psychology (pp. 23-42).

Tajfel, H., Billig, M. G., Bundy, R. P., \& Flament, C. (1971). Social categorization and intergroup behaviour. European Journal of Social Psychology, 1(2), 149-178. https://doi.org/10.1002/ejsp.2420010202

Townsend, S. S. M., Markus, H. R., \& Bergsieker, H. B. (2009). My choice, your categories: The denial of multiracial identities. Journal of Social Issues, 65(1), 185-204. https://doi.org/10.1111/j.1540-4560.2008.01594.x

Weinstein, N., Ryan, W. S., DeHaan, C. R., Przybylski, A. K., Legate, N., \& Ryan, R. M. (2012). Parental autonomy support and discrepancies between implicit and explicit sexual identities: Dynamics of self-acceptance and defense. Journal of Personality and Social Psychology, 102(4), 815-832. https://doi.org/10.1037/a0026854 
IMPLICIT SEXUAL IDENTITY 